\title{
Stability analysis and optimal control of avian influenza model on complex networks
}

\author{
keguo ren $^{1}$, zhang qimin ${ }^{2}$, and Ting Kang ${ }^{3}$ \\ ${ }^{1}$ North Minzu University \\ ${ }^{2}$ School Mathematics and Computer Science, Ningxia University, \\ ${ }^{3}$ Ningxia University
}

September 26, 2020

\begin{abstract}
In this paper, an avian influenza model with saturation and psychological effect on heterogeneous complex networks is proposed. Firstly, the basic reproduction number $\$ \backslash$ mathscr $\{\mathrm{R}\}_{-}\{0\} \$$ is given through mathematical analysis, which is a threshold to determine whether or not the disease spreads. Secondly, the locally and globally asymptotical stability of the disease-free equilibrium point and the endemic equilibrium point are investigated by using Lyapunov functions and Kirchhoff's matrix tree theorem. If $\$ \backslash$ mathscr $\{\mathrm{R}\}_{-}\{0\}<1 \$$, the disease-free equilibrium is globally asymptotically stable and the disease will die out. If $\$ \backslash \operatorname{mathscr}\{R\}_{-}\{0\}>1 \$$, the endemic equilibrium is globally asymptotically stable. Thirdly, an optimal control problem is established by taking slaughter rate and cure rate as control variables. Finally, numerical simulations are given to demonstrate the main results.
\end{abstract}

\section{Hosted file}

2020-09-21.pdf available at https://authorea.com/users/362037/articles/483296-stabilityanalysis-and-optimal-control-of-avian-influenza-model-on-complex-networks 


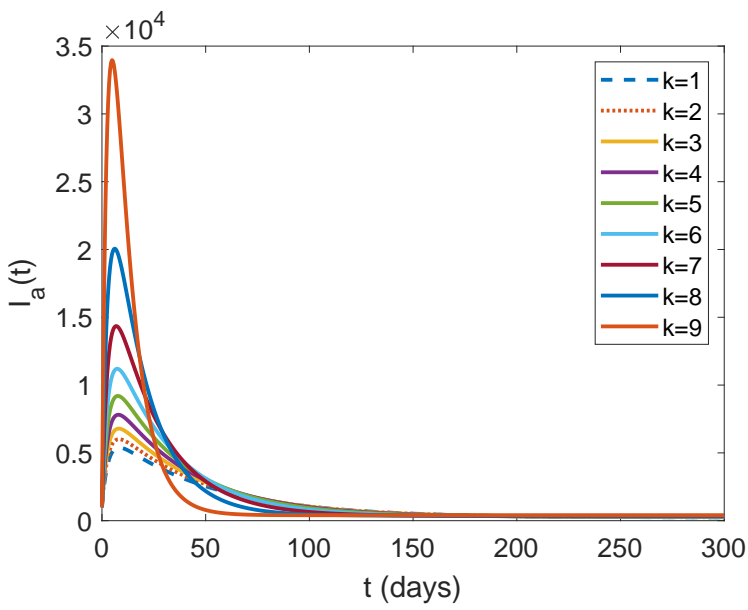




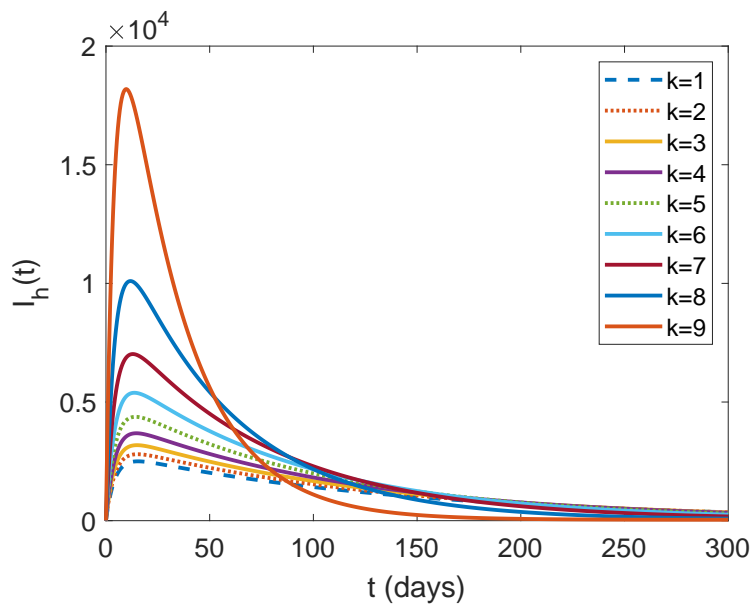




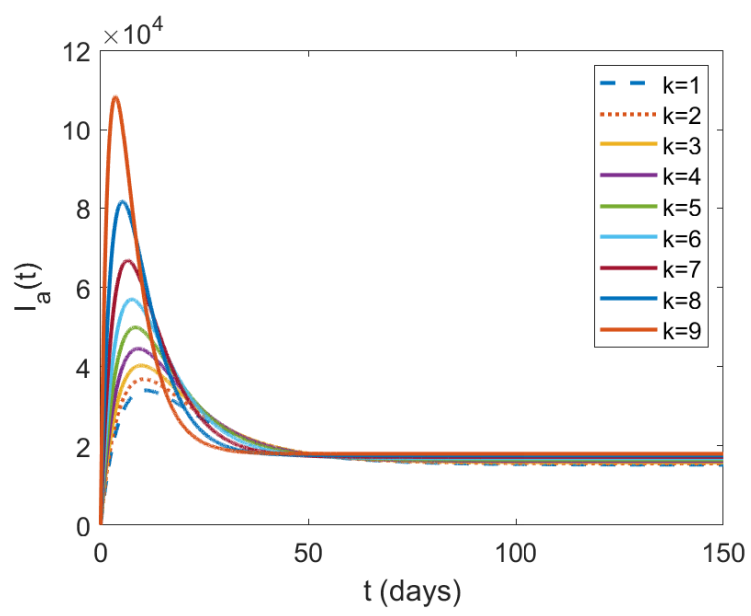




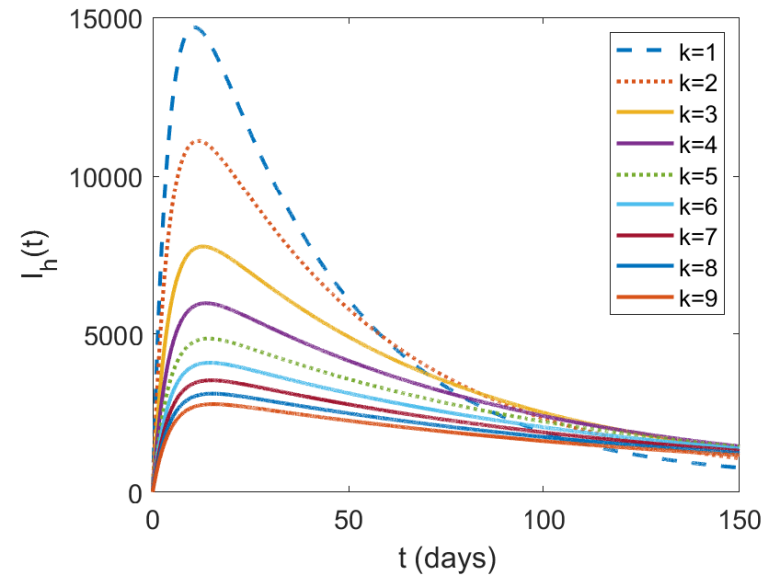

